\title{
Column Chromatography
}

National Cancer Institute

\section{Source}

National Cancer Institute. Column Chromatography. NCI Thesaurus. Code C18242.

A process used for separating mixtures by virtue of differences in absorbency. It involves stationary and mobile phases. The stationary phase was packed in a column with materials that can be of any partitioning capability, adsorption, ion exchange, or affinity. The mobile phase (either liquid or gas) is the mixture that required to be separated. 